\title{
AIDS: It came for the carnival
}

\author{
P D Marsden
}

To an applied research worker like myself whose interest is insect borne protozoa of man AIDS is a different ball game. As a general physician visiting beds in tropical hospitals for 30 years, however, I can't fail to be impressed by this new infectious disease entity. I saw my first patient with the disease at Cornell New York during my sabbatical in 1982 before AIDS was named. The patient came from São Paulo and had lost a lot of weight and was very weak because of a fulminant diarrhoea. His small bowel biopsy specimen showed an unusual appearance at the very surface of the mucosal lining: small nucleated bodies that we know today are the reproductive forms of cryptosporidium. At that stage even this common disease of cattle was known only as a human infection by two references in published work and the oocysts in the faeces of man had still not been detected. Years later when more was known I heard a good presentation on cryptosporidium in Canada by a veterinarian. He had a lovely slide showing him in a white coat but one side of the white coat was brown with faeces from a calf with projectile diarrhoea due to cryptosporidium. It caught him as he was passing. In those early days I advised a few of my students to "get into AIDS" and they have done well, but medicine is doing badly with this difficult virus although the best minds we have are at work.

You see a reflection of this even at those few cocktail parties that I attend in this diplomatic city. AIDS affects the moneyed, the urban, and certain sectors of the artistic side of the community. It is the first urban infectious disease of London this century. At those boring Brasilia cocktail parties where I balance a glass someone occasionally asks me what I do. I say I'm in medicine. What type they ask? Infectious disease is my reply. Now in the old days such a reply usually resulted in peace because they turned away. I wasn't a cardiologist, gastroenterologist, neurologist, or even dermatologist. Apparently I worked on those diseases in the interior of Brazil where they never went anyway because they were afraid of getting infected. Today I have to be more guarded in my reply since it is likely that my questioner will grasp me by the arm, guide me into a corner, and start asking me about AIDS. The replies of course are chilling. No treatment and no prospect in the near future of a vaccine. Its incidence, prevalence, and spread related to the sexual activity of the community. Always a difficult thing to talk about to the uninitiated. The best argument for onanism since the old testament.

Incidence and prevalence figures are more precise where there are good communication systems and competent recorders. The figures from North America, Europe, and Brazil are available to the reader. Although Brazil is now in second place I get the impression that it is still being underreported. It came here with homosexuals from New York and San Francisco coming down for the carnival. Some of the cases I have seen in Brasilia give histories of sexual relations with such visitors even in one instance an American carrying a card with the result of a positive titre serology on it. The great conurbations of Rio and São Paulo were the centres from which it has spread through Brazil and now it is passing from the homosexual to the heterosexual sector of society. At the moment various groups are active in serological surveys using key groups such as prostitutes and haemophiliacs and more general surveys such as blood banks, etc.

\section{Total solace}

Still it is not taken seriously enough here. It is a blight on the lives of the young and a threat to our species. The difficulties that Brazil faces may be illustrated by the examples of two recent patients with AIDS in the ward. The first a 19 year old girl who had gone to earn a little money at a camp in the Amazon basin as a prostitute. The second a gold miner from the same region with suppurating glands and an open lung cavity of tuberculosis as a complication. Both as you see from mining communities in the Amazon. Airfields with planes taking off for secret destinations where there is gold. The gold, usually sedimentary, is of unknown origin. The rocky economy stimulating even more the quest for this precious metal. The conditions of work often so precarious and difficult that it is not surprising workers seek the solace of a woman's arms. But the arms are capped by a death's head-AIDS.

One hypothesis regarding the origin of this retrovirus is that it was brought to Haiti by Haitians working in Africa and then spread via Florida to the large homosexual communities of New York and San Francisco.

Certainly there are precedents - look at the story of the Marburg virus, not to mention Lassa and Ebola. I have worked a lot with monkeys and it was always a mystery to see an important experiment wiped out by what we knew then as the wasting disease, diarrhoea, loss of weight, and failure to thrive. We know how this is due to a specific retrovirus. What will be the effect of AIDS on the endemic infectious diseases of Brazil? In kala azar we have some notion but what of the others I have discussed in these columns? The influence of the immune paralysis induced by HIV seems to favour certain infections as is well shown among the intestinal protozoa.

The lady at the cocktail party says that she can't understand why they haven't done something about it? They, of course, are those who work in infectious disease. The best thing to say is that they are trying and eventually if history repeats itself they will succeed. The conquest of human infectious disease is a story of successes from the time of Pasteur. Today Athenian typhus, Roman malaria, London plague, Philadelphian yellow fever, and Calcutta cholera stand revealed in their true nature.

Meanwhile it's a question of prophylaxis as the Brazilian television is beginning to emphasise, but it's not easy for such a young population compared with the English. I stood in line in front of the Ministry of Health stall on AIDS at a recent fair in Brasilia. Like the 7 year old girl in front of me I received free a condom and much helpful literature on AIDS and sexually transmitted diseases. But how do you reach the man lost in the Brazilian wilderness and if you find him would he take heed? 